\title{
Midwestern United States Census Region
}

National Cancer Institute

\section{Source}

National Cancer Institute. Midwestern United States Census Region. NCI Thesaurus.

Code C76330.

A census region of the United States consisting of Illinois, Indiana, Iowa, Kansas,

Michigan, Minnesota, Missouri, Ohio, Nebraska, North Dakota, South Dakota. 